\section{La violencia juvenil contra emos: análisis etnográfico de su persecución en la Ciudad de México}

\author{
Bullying of emos in Mexico City: \\ an ethnographic analysis
}

\author{
A violência juvenil contra os emos: \\ análise etnográfico de sua perseguição na \\ Cidade do México
}

Daniel Hernández-Rosete 1

doi: 10.1590/0102-311X00080116

\section{Resumen}

El objetivo de este artículo es describir las creencias que han alimentado el odio y las prácticas de violencia, ejercida por diversos sectores, contra varones y mujeres que se identifican a sí mismos como emos en la Ciudad de México. Se trata de un estudio etnográfico, realizado entre 2012 y 2015, apoyado en 24 entrevistas en profundidad a jóvenes estudiantes que en 2008 cursaban algún grado de bachillerato en universidades públicas en la Ciudad de México. Se privilegia la narrativa de los emos (10); sin embargo, se exploraron también los relatos de jóvenes que se consideran punks (6), darks (5) y metaleros (3). Los hallazgos sugieren que las agresiones contra emos tienen un fuerte arraigo en creencias de género, particularmente en la noción de masculinidad hegemónica. Destaca el hecho de que no sólo provienen de colectivos juveniles, también aparece la vida familiar y escolar como contextos de violencia naturalizada y construida como legítima por su vínculo con la noción de disciplina escolar. Las estrategias utilizadas por estos jóvenes para resistir la violencia sugieren posicionamientos reflexivos frente a su contexto histórico, escolar $y$ familiar. Aunque como colectivo lograron colocar su exigencia del derecho a la educación y a la diversidad en aulas universitarias, se advierte la necesidad de diseñar políticas de prevención de violencia, particularmente en contextos escolares universitarios.

Violencia; Sexualidad; Diversidad Cultural

\author{
Correspondencia \\ D. Hernández-Rosete \\ Departamento de Investigaciones Educativas, \\ Centro de Investigación y de Estudios Avanzados del Instituto \\ Politécnico Nacional. \\ Calz. Tenorios 235, Col. Granjas Coapa, Ciudad de México, \\ 14330 - México. \\ danielshr204@yahoo.com.mx \\ 1 Departamento de Investigaciones Educativas, \\ Centro de Investigación y de Estudios Avanzados del Instituto \\ Politécnico Nacional, México DF, México.
}


"Decían que hasta los Beatles eran emos" (chava, dark, 22 años).

\section{Introducción}

La violencia juvenil es un problema de salud pública importante. De acuerdo con un informe del Banco Mundial 1, los jóvenes en México representan cerca del 38\% de las víctimas de homicidios en el país. Otros estudios también realizados en México sugieren que cuatro de cada cien jóvenes han visto afectada su salud a causa de este fenómeno 2 . En ese mismo trabajo se destaca que en varones de entre 25 y 29 años ocurren cerca de 87 homicidios por cada 100 mil habitantes.

Un aspecto polémico del estudio sobre violencia entre jóvenes es que algunas investigaciones consideran que esta es una expresión delincuencial 3,4. Son enfoques de corte biomédico que no sólo criminalizan, sino incluso patologizan a los jóvenes, ya que se les atribuye inestabilidad emocional y agresividad, como si se tratara de actitudes espontáneas y biológicas propias de la edad. La implicación más delicada de este encuadre es que naturaliza un fenómeno que de hecho es cultural e histórico. Esta idea, que considero hegemónica, ha definido los rumbos de los estudios sobre violencia juvenil.

En este trabajo analizo el caso de la agresión que diferentes colectivos emprendieron contra los emos. Para estudiar este fenómeno parto de que la violencia juvenil tiene un origen aprendido, es decir, considero que se trata de un problema social que guarda relación, tanto con las identidades de género, como con las ideas que definen las fronteras identitarias, que construyen para diferenciarse entre sí los colectivos juveniles de emos, punks y góticos.

Las agresiones a emos están poco estudiadas y los trabajos disponibles 5,6 refuerzan el estereotipo siquiátrico que los presenta como jóvenes con tendencias suicidas, sin tomar en cuenta el peso de la discriminación de que fueron objeto. En México son escasos los estudios que documentan la persecución que vivió el colectivo emo, lo que da la impresión de que estas agresiones fueron efímeras y sin trascendencia social. Sin embargo, se trata de un modelo de violencia inherente a la homofobia y de manera más amplia a la discriminación que existe en México 7, documentadas ambas como problemas de salud pública 8 . Por ejemplo, se creyó que toda persona relacionada con la escena emo era gay o lesbiana, por lo que fue sujeta a violencia pública. Además, por su presunta falta de originalidad en el vestir, se les tomó como plagiarios de la escena punk y dark, lo que contribuyó a estigmatizarles. También fueron asociados a cuadros clínicos de depresión y con prácticas suicidas. Esta ideología fue reproducida en la vida familiar, vecinal y sobre todo escolar, al punto en que caminar por la calle era un acto temerario, porque cualquier persona podía proferir insultos o agredir físicamente a quien mostrara algún indicio de pertenencia a la escena emo.

Pero lo que hace compleja a esta violencia es su aceptación social. De ahí el interés por analizar las creencias que alimentaron el odio y las agresiones ejercidas por diversos colectivos sociales contra varones y mujeres que se identificaron a sí mismos como emos en la Ciudad de México. Además, se analizan las estrategias utilizadas para resistir y enfrentar las prácticas de violencia ejercidas contra ellos desde la vida familiar y escolar en la Ciudad de México.

\section{Marco teórico}

La violencia entre jóvenes expresa relaciones de género, pues ocurre en contextos de significado apegados a los estereotipos de masculinidad, en donde ser violento es un recurso de prestigio social 9 y, a la vez, una forma de legitimación. Pero la violencia masculina no sólo puede ser entendida como una construcción social, ya que implica relaciones de poder asimétricas que naturalizan la agresión 10, especialmente la homofóbica y la misógina. Así, ser hombre violento es una condición adquirida que expresa formas aprendidas de ser "hombre verdadero" 11, pero, además, favorece la necesidad social de ser reconocido como tal por otros varones.

Otro aspecto a destacar es que la violencia masculina se reproduce en la vida cotidiana como una forma de teatralidad, ya que existe como un espectáculo en donde la mirada entre varones es definitoria del estatus social. Es decir, se aprende a ser violento a través del aval que otorga la mirada pública 
de otros, por eso, esta violencia expresa las normas masculinas que definen los usos del cuerpo y su relación con el ejercicio del poder masculino.

En este trabajo se considera que ser violento no es sólo un hecho aprendido 12,13,14, además se trata de un recurso de producción de honor masculino. Estas creencias favorecen la existencia de prácticas de vigilancia heteronormativa, es decir, de miradas que buscan expresiones eróticas que no coincidan con los mandatos ligados a la vida sexual con fines reproductivos. Creo, por eso, que la vigilancia heteronormativa es una forma de violencia de género, cuya eficiencia radica en su condición persecutoria y correctiva, pues funge como catalizador y a la vez legitimador de la violencia, dado que se agudiza cuando se transgreden los parámetros de identidad sexual considerados normales. Esto es muy evidente cuando la práctica de la sexualidad no coincide con los estereotipos de género 15, pues surgen formas de intolerancia que fácilmente propician prácticas de persecución de los colectivos disidentes 16, y de personas cuyos atributos sociales son vistos como anormales 17. Por eso, en este trabajo analizo la violencia ejercida contra emos tomando en cuenta la perspectiva de género y de estudios sobre masculinidad, pues los emos, hombres y mujeres, fueron vistos como transgresores del sentido mismo de la identidad sexual, asumida como verdadera o hegemónica 18 , es decir, de aquella orientada a la reproducción humana.

\section{Método, técnicas de investigación y universo de estudio}

El propósito fue acercarme al análisis de la persecución de los emos desde la perspectiva de los propios actores; de modo que el estudio es de corte etnográfico y está inscrito en la corriente fenomenológica del constructivismo social, con el que se exploraron los universos de sentido y significado 19 a través de entrevistas en profundidad. Estas iniciaron como conversaciones informales y fueron grabadas con el consentimiento informado de quienes participaron en el estudio, con el compromiso de mantener, como un derecho suyo, el anonimato y la confidencialidad.

Las entrevistas y las observaciones etnográficas se llevaron a cabo entre enero de 2012 y junio de 2015. El estudio recupera la oralidad de 24 jóvenes estudiantes que en 2008 cursaban algún grado de bachillerato en universidades públicas en la Ciudad de México y, si bien se privilegia la narrativa de los emos (10), también se exploraron los relatos de jóvenes que se consideran punks (6), darks (5) y metaleros (3). Entrevisté a integrantes de diferentes colectivos, con el fin de comprender sus creencias y puntos de vista sobre las agresiones a los emos, especialmente las razones con que justifican y avalan la persecución de este colectivo.

El dilema más complejo que enfrenté como antropólogo tuvo que ver con la definición de lo emo, por eso fui cuidadoso de no adscribir a los informantes a ningún contexto identitario, considerando sólo su aspecto físico. Así me apegué a Weber ${ }^{20}$, quien considera que la identidad comunitaria tiene que ver con el sentimiento individual de pertenencia a un colectivo. Con base en este planteamiento consideré que ser emo puede implicar un proceso de adscripción comunitaria atribuido por otros, pero también es un acto de autoadscripción, o sea, es una forma de elección social inherente al individuo.

\section{Estrategias y dilemas de recolección de información}

Los primeros emos que pude entrevistar se mostraron sumamente renuentes a reconocerse como tales, por lo que no aceptaban hablar sobre sus experiencias. Con el tiempo pude entender por qué no querían nombrar su pasado: la mayoría había sido rechazada al identificarse abiertamente como emo. Este fenómeno fue narrado por los informantes como una vivencia muy arraigada en sus recuerdos, particularmente en contextos de cortejo:

"Cuando platicas con una chica y te pregunta ¿eres emo?- y si tú dices que sí, a lo mejor ella te había considerado en ese momento como un prospecto. Pero ya después, por haberle dicho que eres emo, cambia totalmente su perspectiva" (varón, emo, 22 años, actualmente estudiante de licenciatura).

Los primeros emos que entrevisté me ayudaron a establecer contacto con más jóvenes dispuestos a platicar, pero también implementé nuevas estrategias para escucharles. Una de éstas fue el uso del Facebook y su sistema para conversar en el chat, que es mucho más informal y anónimo, por lo que 
se disuelve la rigidez que implica hablar con un antropólogo cara a cara. Además, hace más fácil retomar la entrevista con preguntas de seguimiento o con nuevas interrogantes sin que el reencuentro se vuelva un protocolo formal. Finalmente, pude ser invitado a sus fiestas, lo que me permitió ser identificado por algunos miembros del colectivo. Esto me ayudó a acercarme de manera más nítida al conocimiento situado del mundo emo y poder escuchar narraciones sobre sus vidas familiares o los gustos musicales y las estéticas corporales; pero sobre todo logré comprender la magnitud y el efecto de la discriminación en sus vidas.

Las entrevistas se realizaron en sitios sugeridos por los informantes en la Ciudad de México. El más trascendente fue la glorieta del Metro Insurgentes, una estación nodal del metro de la ciudad que, debido a su carácter de interconexión, es un punto de convergencia de habitantes de zonas perimetrales del área urbana y que ha derivado en un espacio de reunión de diversos colectivos juveniles. Pero sobre todo se trata de un espacio históricamente significativo para este estudio, porque ahí ocurrió una de las agresiones más contundentes contra los emos, pues el 16 de marzo de 2008 se les pretendió despojar del derecho a reunirse en ese lugar.

\section{La persecución de emos y el contexto nacional}

El 7 de marzo de 2008 ocurrió la primera agresión en la Plaza de Armas de Querétaro. Sólo unos días después, el 16 de marzo, se dio otra en la glorieta del Metro Insurgentes, en la Ciudad de México. Pocos días antes de estos sucesos había aparecido un llamado a nivel nacional, dirigido a jóvenes de diversas subculturas urbanas. El aviso se propagó a través de las redes sociales, principalmente Facebook, My Space y YouTube; la idea era agredir a todo sujeto ligado a la escena emo. El fenómeno creció con rapidez, pues los informantes mencionan agresiones simultáneas en urbes de rango medio que, con excepción de la capital (Ciudad de México), estaban gobernadas por regímenes autoritarios y apegados a preceptos católicos, propios de sectores conservadores, como la ciudad de Guadalajara, Puebla y Querétaro.

No obstante, en opinión de los emos, darks y punks, la violencia fue incitada mediáticamente, pues la televisión fungió como detonante del rechazo social, ya que el conductor de un programa para jóvenes descalificó la escena emo, utilizando un lenguaje ofensivo que reforzaba estereotipos de género 21 y que incitaron al odio social, lo que detonó parte del proceso persecutorio 22.

En general, el ambiente de persecución convocaba a diversos colectivos juveniles a agredir a quienes fueran considerados miembros del escenario emo. Se creía en el supuesto vacío ideológico, estético y existencial que, desde la noción de "tribu urbana", caracterizaba presuntamente a los emos. Sin embargo y a manera de hipótesis de trabajo, nos preguntamos si la intolerancia hacia los emos expresa más bien un rechazo de corte homofóbico contra los entonces nuevos indeseables, reconocidos a través de su aspecto físico.

Las agresiones físicas a las mujeres además tenían una marcada connotación misógina. Una mañana, frente a la Preparatoria, una chica se encontró con un ciclista que además de insultarla, le tocó un seno. La chica vio una patrulla estacionada justo enfrente y corrió a ella para denunciar al agresor ante los policías; pero lo que obtuvo fue una segunda agresión, de carácter verbal, pero quizá tan grave o más que la de aquel hombre en bicicleta: "A eso se exponen por andar con esa vestimenta tan emo. Además, no puedo detener al agresor porque ya no está”. La chica se retiró dudando de que su aspecto emo fuera el detonante de las agresiones.

Estas agresiones son en realidad un excelente recurso para exonerar al Estado de la persecución ejercida en un contexto de gobernanza, marcado por el conservadurismo religioso, tan característico de los gobiernos en esa época. Además, parecen haber actuado desde la omisión, ya que no detuvieron el ambiente de linchamiento que, al decir de una informante, pudo haber tenido una función política:

"En las putizas a los emos no participaron todas las bandas. Los darks los protegíamos en el Chopo, o sea nosotros sí les dábamos el paso libre al Chopo. No había consenso, muchos sí los odiaban, otros los apoyábamos. Entonces fue una manera, creo yo, de contrapuntear a los jóvenes, para distraer de la situación del país" (mujer, dark, 19 años). 
No necesariamente hay una relación entre la persecución social a los emos y la represión que en ese momento ejercía el Estado contra el Sindicato Mexicano de Electricistas, pero esta pugna política se vio opacada temporalmente por los incidentes de violencia contra los emos.

\section{Creencias sobre pureza y contaminación. La aparición del emo en la escena juvenil}

Entre los jóvenes entrevistados está la idea de que los emos no tienen adherencia a ningún principio de identidad colectiva ni estética propia, mucho menos se les concibe como parte de un movimiento juvenil, como sí parece ser el caso de darks y punks:

"....Mira, el movimiento punk no está en contra de la moda emo; nuestro desmadre es contracultural y no sólo temporal como el de ellos. Nosotros ya tenemos más de 30 años en el movimiento punk y eso que se desató de emos contra todas las tribus, pues para serte sincera al punk le tiene sin cuidado. Esos morros no nos importan" (estudiante de preparatoria, 19 años, punk).

Según este planteamiento, la escena emo es sólo una efímera moda que surge por imitación de otras corrientes y, además, carece de bagajes ideológicos y políticos:

"El emo no refleja una filosofia, no hay una estética propia. No me molesta que me confundan con un emo en la calle, pero prefiero que no lo hagan y es que los emos nos copian el estilo, la forma de vestir. Los emos no visten de negro, pero los góticos sí. Uno evoluciona, el punk muere y nace el gótico, pero el emo no trae tradición" (varón punk, administrador de bar punk).

La presunta falta de historicidad del colectivo surge como otro sustento de la discriminación, es decir, se descalifica a la escena emo, porque no aporta innovación estética y se cree que sus atributos siempre son tomados de otros colectivos: los pantalones de crewel en el más claro estilo rockabilly, o los cortes de pelo extraídos del hardcore. Este argumento sugiere la existencia de creencias sobre contaminación y tabú 23 , lo que ayuda a comprender que el miedo y odio a los emos tiene su origen en el pensamiento binario que confronta lo limpio a lo sucio: "nuestro comportamiento ante la contaminación es la reacción que condena cualquier objeto o idea que tienda a confundir o a contradecir nuestras preciadas clasificaciones de pureza" 23 (p. 54).

De ahí que el emo haya sido concebido como una amenaza a cualquier identidad concebida como pura. Por eso, creo que el concepto de tribu urbana pudo contribuir a agudizar el odio contra los emos, pues algunos colectivos sí se apegaron a la idea de pureza tribal inherente a la idea de tribu urbana que, como ya he mencionado, presuntamente caracteriza a cada escena (especialmente darks, góticos y punks). Es decir, las ideas que clasifican a los colectivos urbanos a partir de sus adscripciones de identidad nosotros-ellos, propios de la lógica tribal, expresan la carga de una clasificación simbólica de efectos discriminatorios, pues lo emo fue considerado como carente de los cercos identitarios que lo harían un movimiento único y sobre todo auténtico en función de su pureza:

“...Para empezar los emos eran los clásicos niños de 14 años que llegaban con el peinado de The Cure, pero traían pantalones de punk. Nosotros veíamos la camisetita de niño fresa y las uñitas pintadas como gótico, órale, ¡vientos! Entonces ¿qué eres? ¿Gótico, punk? ¿Qué eres, fresita? ¿A ver tu música? Happy punk. Órale, o sea tu música no tiene calidad, no tienes originalidad, estás copiando estilos de todas las tribus. No tienen una cultura definida ¿y luego, tu actitud? Pues mi actitud es deprimente como los darkis, ¿por qué? No pues porque traemos luto interno ¿no? Si vas a copiar de nosotros, pues copia lo chido ¿no?, la cultura, la educación. Si vas a copiar de los punks, pues fijate qué son los punks, o sea infórmate quién es cada tribu. Para que puedas portar algo de ellos, de su cultura. O sea, creo que los emos tampoco dejan mucho a la sociedad" (varón, dark, 22 años, estudiante de licenciatura).

En el fondo el problema no tenía que ver con el hecho de que los emos no tuvieran propuesta estética, sino que esta carencia los llevó a un acto de eclecticismo en el vestir. Es decir, el hecho de mezclar estilos fue visto como un acto de contaminación identitaria, lo que por décadas había sido evitado obsesivamente, pues la ropa constituye el anclaje visual necesario para diferenciar a darks de punks o a góticos de metaleros.

Y sin embargo, la violencia contra ellos va mucho más allá de la presunta falta de pureza en la propuesta estética o de su aparente indiferencia política. Los testimonios sugieren que es el rechazo a la diversidad sexual uno de los aspectos que justifican la violencia juvenil contra este colectivo: 
"La gente confunde estilo emo con el punk, pero los emos caen en excesos en vía pública, beben alcohol y particularmente molesta su homosexualidad y su bisexualidad” (varón, punk, 20 años, estudiante de licenciatura).

El emo, considerado a partir de su modo de vestirse, maquillarse y tatuarse, aparece en el imaginario social como un ser anómalo, pero lo que más perturba es su franca apertura al noviazgo bisexual y a un performance ambiguo sobre el género que le confiere el carácter andrógino:

"Nunca me he considerado lesbiana, aunque anduve con dos chavas. Allá en Los Sillones, un bar que estaba cerca del metro Insurgentes era siempre un punto de encuentro, hasta entraban punks y darks, habia de todo. Ese bar era como nuestra casa pero sin gritos de padres castrantes, era el lugar de apertura, nadie te criticaba y pues como la gente casi siempre te anda encasillando, al principio no sabian si yo era hombre o mujer, decían que era lesbiana. Pero como también estuve con chavos pues decían que era gay. Ahora sí me siento bien andando sólo con hombres, pero no veo mal andar con una morra, de hecho disfruté más cuando anduve así, con una chava" (mujer, emo, 21 años, estudiante de licenciatura).

Entre los aspectos que parecen abonar a lo emo como movimiento social está precisamente su irreverencia ante los estereotipos de la vida sexual, definida desde los márgenes heterosexual u homosexual. Creo que su aportación tiene que ver con el erotismo, ya que los noviazgos son referidos como prácticas abiertas que dan lugar a una idea de sexualidad propia del terreno de lo andrógino.

Por eso cobra interés sociológico la persecución de los emos, pues no sólo se sustenta en la concepción de pureza sobre lo que debe ser un movimiento juvenil, sino además en un conservadurismo que no tolera la ambigüedad sexual inherente al estilo andrógino del emo. Lo que paradójicamente otorga a lo emo un carácter de resistencia contracultural único frente a una sociedad vigilante de todo aquello que es tenido como anormal.

Cabe recordar que cuando inicié el trabajo de campo fue difícil que los emos se asumieran como tales. Esta renuencia quizá tuvo que ver con el miedo a la muerte social, que es una consecuencia del estigma y, según Thomas 24 , lleva al sujeto a romper vínculos de pertenencia con el mundo social cuando es denigrado, proscrito o desterrado, debido a algún atributo culturalmente tenido como anormal. El erotismo que se describe como parte de su vida cotidiana parece haber tenido un efecto perturbador, especialmente en el ámbito de la vida familiar y escolar.

\section{La producción social del estigma. Patologización, vida escolar y entramados familiares}

Aunque la violencia contra los emos parece provenir de otros jóvenes, las historias narradas muestran dos instituciones particularmente agresivas, cuyo hostigamiento es invisible por el carácter de legitimidad que adquieren sus prácticas disciplinarias: me refiero a la familia y a la escuela. Estas instituciones ejercen formas de vigilancia heteronormativa, entendida como la práctica disciplinaria que busca eliminar o corregir toda identidad que, por transgredir los códigos de género socialmente aceptados, represente una amenaza a las normas sexuales. Se trata de una violencia institucionalizada que descansa en dos pilares, la idea de decencia y disciplina como factores determinantes de la buena educación. Ambos están intrínsecamente ligados a los estereotipos de género 25 y se constituyen en un referente normativo, cuya praxis radica en la corrección, pues según afirma Canguilhem 26, lo que se pretende normalizar siempre es todo aquello que transgrede la norma: "no es la excepción la que confirma a la regla como regla, sino la infracción la que le da oportunidad de ser regla al corregir. En este sentido, la infracción no es el origen de la regla, sino el origen de la regulación. En el orden de lo normativo, el comienzo es la infracción" 26 (p. 189).

En este sentido, la familia y la escuela pueden llegar a reproducir el orden histórico de la homofobia y la misoginia que, según Foucault 27, existe a fuerza de nombrar y clasificar todo aquello que es tenido como anormal. Un claro ejemplo es la depresión, que es vista como el rasgo distintivo del ser emo y deviene en el síntoma que le estigmatiza. Éste es quizá uno de los miedos sociales más vigentes, porque la depresión es tenida como una enfermedad mental y representa el fantasma de la locura, el miedo social a la sinrazón:

“...A veces hacíamos cutting, nos cortábamos la piel y nos tomaban como chavas que tenían enfermedades psicóticas que trataban de comunicar algo, pero no podían entender que nuestros problemas no tenían que ver 
con ser o no emos. Muchas habíamos vivido abusos sexuales y violencia familiar cabrón, pero eso no importaba, el problema es que éramos emos" (mujer, emo, 22 años, estudiante de licenciatura).

El emo, imaginado como un ser deprimido, no sólo encarna al sujeto diferente, además es particularmente perturbador para un ambiente escolar presuntamente ajeno a todo problema de salud mental:

"El profe de siete de la mañana no me dejaba entrar si llegaba toda glamorosa como emo, pero sí dejaba pasar a las pinches punks, a las góticas, pero no a las que según él éramos gente enferma, así hasta que con tres faltas te quitaba el derecho a examen. Cuando reprobé mi mamá fue a hablar con él, el profe le dijo que yo necesitaba ayuda porque era emo, que estaba siempre deprimida. Pero la violencia que sufrí en la secundaria y la violencia que habia en mi casa no contaban, mi papá se burlaba de mi y mi mamá creía que yo estaba todo el tiempo deprimida, me decía que iba a ser una mediocre, porque reprobé un año cuando iba en la secundaria" (mujer, emo, 21 años, estudiante de licenciatura).

Si bien la patologización surge con el miedo al aspecto físico y empieza con el diagnóstico basado en el aspecto físico, lo paradójico es que es el profesor quien clasifica y determina la enfermedad mental a partir de conductas "indeseables", cuyas evidencias se remiten al cuerpo con tatuajes, piercings y expansores, especialmente con perforaciones en labio y lengua. Entre los más inquietantes para una sociedad tan poco tolerante ante el cuerpo diferente es, sin duda, el piercing en septum nasal, aquel que atraviesa la base de la nariz:

"Para qué entregar tareas y reportes si el profesor de biología ya me había amenazado por usar piercings en nariz y lengua. Para qué entrar a una clase en la que desde el primer día de clases me regañó, todas sus pinches bromitas mamonas tenían que ver con que según él me escondo atrás del pelo y que los piercings en la lengua y en la nariz sólo los usaron los esclavos. Siento que nos tienen miedo, porque el emo representa todo eso a lo que la sociedad le teme" (mujer, emo, 19 años, estudiante de licenciatura).

Estas prácticas generan un círculo perverso de estigmatización y discriminación que favorece el retraso escolar, pero que no es fácilmente identificable. Paradójicamente, el único que tiene claro este cerco es el alumno emo que lo vivió, pero su voz carece de credibilidad social. Es el propio emo (en su condición de estudiante) quien cobra conciencia de lo siniestra que puede ser la muerte social, porque se agudiza con la reprobación escolar.

Establecido el consenso sobre el diagnóstico de la depresión (una creencia que de facto hace legítima la idea de que el emo es una persona enferma), la vida familiar prácticamente se vuelve una extensión de la escuela, pues tiene la encomienda de atender y hacer atender a ese joven enfermo que vive en casa. Así, familiares, personal docente y administrativo emprenden una cruzada contra cualquier rasgo que delate al emo, a tal punto que los informantes recurrieron a la simulación en la forma de vestir y peinarse:

"Era emo, pero no me dejaban vivir así en mi casa porque decían que estaba loca. La reunión en el metro Insurgentes era ya desde el jueves y el viernes, pero lo más pesado era el sábado porque el domingo había que chingarse haciendo tareas y trabajos escolares. Pero como no me dejaban en mi casa ser emo entonces tenía que ingeniármelas y le mentía a mi mamá: 'Mamá, mañana tengo que hacer un trabajo' y ella me decía. 'Sí claro hija, vete a hacer el trabajo, qué bueno que ya estás retomando la escuela.' 'Sí, me voy a llevar una mochila'. Pero entonces me revisaba la mochila y por eso antes de que la revisara yo aventaba mis cosas por la ventana, así salía de mi casa con mi mochila con libros y luego abajo tenía que meter las cosas que estaban tiradas en la calle. Era un desmadre tener que meterlas en la mochila para irme a Insurgentes. Ya en Insurgentes apagaba el teléfono. Como eran casi dos horas de camino, pues de mi casa salía con el cabello ya planchado, lo que era una fortuna. Nada más tenía que hacerle una colita y ya para que no se maltratara tan cabrón, ya entre mis cosas iba la cera, el peine, el maquillaje, y el cinturón con estoperoles, porque mi mamá no me dejaba usarlos" (mujer, emo, 19 años, estudiante de licenciatura).

Una práctica de discriminación escolar bastante común consistía en negar el acceso al plantel exclusivamente a las emos, aun identificándoles como estudiantes. Los testimonios sugieren que eran trabajadores sindicalizados quienes reproducían las prácticas de algunos docentes en el aula, es decir, clasificaban a los alumnos y, según su aspecto, decidían si eran o no emos:

“...No me dejaban entrar, mostraba mi credencial pero no les importaba, eran trabajadores del sindicato $y$ nos negaban el paso, porque sabian que el director los apoyaba. El director de la prepa no quería a los emos y por eso dejaban pasar a todas las bandas, pero a nosotros no. Hasta que decidí no entrar a la primera clase, la de las siete de la mañana. Llegaba como siempre, bien temprano. Antes de las siete ya estaba en la escuela, pero iba 
toda escurrida, sin maquillaje y vestida normal. Traía todo escondido en la mochila y como me tardaba casi una hora en arreglarme me metía al baño y cuando salía ya para la segunda hora de clase nadie me reconocía. Unos creían que había pasado la noche en el baño de la prepa" (mujer, emo, 21 años, estudiante de licenciatura).

Era casi imposible escapar al escrutinio de una mirada dispuesta a erradicar lo que consideraba anormal. Sin embargo, los testimonios muestran la creatividad con que estos jóvenes lograron resistir esta violencia estructural e institucionalizada, aunque reconozco que, quizá, la discriminación más severa es la que se da entre jóvenes que creen en los cánones estéticos y que forman colectivos de identidad de cara a la vida escolar cotidiana. Entre ellos fueron muy recurrentes los reclamos que se hicieron a los emos respecto a su presunta falta de autenticidad estética.

Este rechazo no es un asunto menor, pues existen estudios que revelan la importancia que otorgan los diferentes colectivos juveniles al sentido de pureza estética como mecanismos de legitimación y de agregación social 28,29,30. Pero lo que es de destacar es que este discurso sobre pureza penetró los ambientes escolares, pues en los patios escolares se convertían de facto en arenas de discusión sobre pureza y estilo.

En el ámbito de la interacción escolar universitaria también encontré que los emos habían sido agredidos por gente supuestamente crítica del sistema escolar y familiar represor. Algunos agresores solían participar anualmente en la histórica marcha del 2 de octubre, que existe en México como emblema de la memoria social en contra de la matanza de estudiantes, perpetrada por el Estado en 1968, enarbolando consignas pacifistas y en contra de la violencia social, pero que parecen vivir apegados a una opinión pública que se crea a través de la televisión:

"Nos exterminaron a los emos, nos acabaron, fueron aquellos que decían que el Estado mexicano había asesinado estudiantes en el 68, esos mismos que han salido hipócritamente a marchar año tras año gritando que el 2 de octubre no se olvida. Son los mismos que vaciaron en nosotros todo su resentimiento social, toda la hipocresía y contradicción. Se dicen críticos y se fueron enterando de nosotros sólo a partir de Televisa" (mujer, emo, 22 años, estudiante de licenciatura).

Aunque la depresión, la homosexualidad y la carencia de conciencia social fueron considerados los atributos de lo emo, en los testimonios de estos jóvenes se advierte un posicionamiento ciudadano que deja entrever una retórica crítica, muy necesaria para oponerse a un régimen opresivo, especialmente intolerante con jóvenes que cuestionaron los estereotipos de género, tanto como los modelos de autoritarismo escolar y familiar.

\section{Conclusiones}

Analizar el miedo al otro impone desafíos sociológicos, porque la gente no se concibe a sí misma como etnocéntrica, particularmente cuando se trata de minorías juveniles que creen vivir con ideas progresistas y con apertura al mundo, como los punks y los darks. Este dilema incluye la paradójica situación de hallar experiencias de intolerancia en escuelas públicas de educación media superior, cuyo ambiente debería regirse por un humanismo incluyente y reflexivo. Pero ni la escuela, ni la condición de ser joven ligada a algún escenario contestatario, lograron superar el miedo a la otredad que representaba el emo.

Las narrativas sugieren que los emos son un colectivo con identidades sexuales ambiguas. En nuestra sociedad lo andrógino, como cualquier otro estado de intersexualidad o ambigüedad de género que sugiera la existencia de una ambivalencia genital o identitaria, está sujeto a persecución. Así, los emos surgen en una sociedad mexicana que aún no terminaba de asimilar la existencia pública de la homosexualidad, cuando su colectivo asume una forma más excéntrica de vivir la sexualidad. Es precisamente por eso que los emos pueden ser vistos como un colectivo de disidencia contracultural, pues tienen prácticas más laxas, porque igual son bisexuales, homosexuales o heterosexuales.

Las entrevistas sugieren que la formación ideológica de algunos docentes puede incidir en las prácticas de vigilancia heteronormativa escolar, pues los relatos muestran que los profesores pueden estigmatizar a los estudiantes que transgreden las identidades de género socialmente aceptadas. En este sentido, una de las formas de violencia más invisibilizadas que experimentaron los emos se origina con la mirada disciplinar del profesor, quien patologiza desde el aula y con base en prejuicios morales. 
No obstante que el colectivo emo reivindicó el derecho a la diferencia desde una praxis de resistencia contracultural, se advierte la necesidad de diseñar políticas de prevención de violencia en ámbitos escolares públicos, particularmente dirigidos a personal académico y administrativo. Paradójicamente, los contextos escolares referidos en este estudio son escuelas representativas del Estado que no están exentas de expresiones de odio social de poblaciones tenidas como socialmente diferentes.

\section{Agradecimientos}

Agradezco a los jóvenes que aceptaron contarme su vida para documentar la historia de resistencia contracultural en tiempos violentos en México. También agradezco el apoyo en trabajo de campo de mis colegas Nicoline Miskow Friborg y Axel Bautista. Me siento agradecido con el Departamento de Investigaciones Educativas del Cinvestav por el apoyo brindado, al ofrecer condiciones idóneas para realizar trabajo de campo de corte etnográfico. Finalmente, dedico este trabajo a quienes han resistido formas de persecución social y de Estado.

\section{Referencias}

1. Banco Mundial. La violencia juvenil en México. Reporte de la situación, el marco legal y los programas gubernamentales. http://wwwwds.worldbank.org/external/default/WDS ContentServer/WDSP/IB/2012/11/29/00035 6161_20121129060725/Rendered/PDF/Non AsciiFileName0.pdf.

2. Valdez-Santiago R, Hidalgo-Solórzano E, Mojarro-Íñiguez M, Rivera-Rivera L, Ramos-Lira L. Violencia interpersonal en jóvenes mexicanos y oportunidades de prevención. Salud Pública Méx 2013; 55:259-66.

3. Akiyama C. Understanding youth street gangs. J Emerg Nurs 2012; 38:568-70.

4. Clements PT, Akiyama C. Youth gangs: reason for concern. J Forensic Nurs 2011; 7:105-7.

5. Baker F, Bor W. Can music preference indicate mental health status in young people? Australas Psychiatry 2008; 16:284-8.

6. Definis-Gojanović M, Gugić D, Sutlović D. Suicide and emo youth subculture: a case analysis. Coll Antropol 2009; 33 Suppl 2:173-5.

7. Ortiz-Hernández L, Valencia-Valero RG. Disparidades en salud mental asociadas a la orientación sexual en adolescentes mexicanos. Cad Saúde Pública 2015; 31:417-30.

8. Semple S, Stockman JK, Goodman-Meza D, Pitpitan EV, Strathdee SA, Chavarin CV, et. al. Correlates of sexual violence among men who have sex with men in Tijuana, Mexico. Arch Sex Behav 2016; 46:1011-23. 
9. Burgois P. In search of respect: selling crack in El Barrio. Cambridge: Cambridge University Press; 2003.

10. Gutmann M. Ser hombre de verdad en la ciudad de México: ni macho, ni mandilón. México DF: El Colegio de México; 1998.

11. Connell RW, Messerschmidt JW. Hegemonic masculinity: rethinking the concept. Gend Soc 2005; 19:829-59.

12. Bourdieu P. La dominación masculina. Barcelona: Anagrama; 2005.

13. Gutmann M. The ethnographic ambit: women and the negotiation of masculinity in Mexico City. Am Ethnol 1997; 24:833-55.

14. Godelier M. La producción de los grandes hombres. Poder y dominación masculina entre los Baruya de Nueva Guinea. Madrid: Akal; 1986.

15. Butler J. Bodies that matter. New York: Routledge; 1993.

16. Girard R. El chivo expiatorio. Barcelona: Anagrama; 2000.

17. Foucault M. La vida de los hombres infames. La Plata: Altamira; 1996.

18. Butler J. Gender trouble. New York: Routledge; 1990.

19. Berger T, Luckmann P. La construcción social de la realidad. Buenos Aires: Amorrortu; 2003.

20. Weber M. Economía y sociedad. México DF: Fondo de Cultura Económica; 1999.
21. Verdades del movimiento Emo. https://www. youtube.com/watch?v=EHIYGPJbbAE (accedido el 03/Mar/2015).

22. Girard R. La violencia y lo sagrado. Barcelona: Anagrama; 2002.

23. Douglas M. Pureza y peligro: un análisis de los conceptos de contaminación y tabú. Buenos Aires: Nueva Visión; 2007.

24. Thomas L. Antropología de la muerte. México DF: Fondo de Cultura Económica; 1983.

25. Rubin G. El tráfico de mujeres: notas sobre la economía política del sexo. Nueva Antropología 1986; 8:95-145.

26. Canguilhem G. Lo normal y lo patológico. México DF: Siglo XXI; 2009.

27. Foucault M. Los anormales. Buenos Aires: Fondo de Cultura Económica; 2009.

28. Maffesoli M. El tiempo de las tribus. Barcelona: Icaria; 1990.

29. Reguillo R. Emergencia de culturas juveniles: estrategias del desencanto. Bogotá: Norma; 2000.

30. Urteaga M, Ortega E. Identidades en disputa: fresas, wannabés, pandros, alternos y nacos. In: Reguillo R, Feixa C, Valdez M, coordinadores. Tiempo de híbridos: entre siglos jóvenes México-Cataluña. México DF: Instituto Mexicano de la Juventud; 2004. p. 114-32. 


\section{Abstract}

The article describes the beliefs that have fueled violence by various groups against male and female "emos" in Mexico City. This was an ethnographic study from 2012 to 2015 based on 24 in-depth interviews with young students enrolled in public universities in Mexico City in 2008. The study focused primarily on emos (10), but also included young people that described themselves as punks (6), darks (5), and rockers (3). The findings suggest that bullying of emos is deeply rooted in gender beliefs, particularly hegemonic notions of masculinity. The study highlights the fact that bullying is perpetrated not only by other youth, but also occurs in the family and school settings, where the violence is taken for granted as a legitimate construct associated with the idea of discipline in school. The strategies used by these young people to resist bullying suggest reflexive attitudes towards their historical, scholastic, and family contexts. They are able to reaffirm their collective demand for the right to education and diversity in university classes, but the situation calls for policies to prevent bullying, especially in the university community.

Violence; Sexuality; Cultural Diversity

\section{Resumo}

O artigo teve como objetivo descrever as concepções que têm alimentado o ódio e as práticas de violência, exercidas por diversos setores, contra homens e mulheres que se identificam a si mesmos como emos na Cidade do México. Trata-se de um estudo etnográfico, efetuado entre 2012 e 2015 , sustentado em 24 entrevistas em profundidade a estudantes jovens que em 2008 cursavam algum grau dos últimos anos do ensino secundário nas universidades públicas da Cidade do México. Prioriza-se a narrativa dos emos (10); não entanto, se exploraram também os relatos dos jovens que se consideram punks (6), darks (5) e metaleiros (3). As conclusões sugerem que as agressões contra emos tem uma forte conexão com a percepção de gênero, particularmente ao respeito do conceito de masculinidade hegemônica. Destaca-se o fato de que não apenas emanam do coletivo juvenil, também emergem na vida familiar e escolar como contextos de violência naturalizada e construída como legítima, por causa do seu vínculo com a noção de disciplina escolar. As estratégias empregadas por estes jovens para resistir a violência sugerem posicionamentos reflexivos frente a seu contexto histórico, escolar e familiar. No entanto, como coletivo lograram colocar sua exigência ao direito a educação e a diversidade nas aulas universitárias, adverte-se a necessidade de desenhar politicas de prevenção a violência, especificamente nos contextos escolares universitários.

Violência; Sexualidade; Diversidade Cultural

Recibido el 13/May/2016

Versión final presentada el 03/Mar/2017

Aprobado el 22/Mar/2017 